\title{
O DESAFIO NA ESCOLHA DOS SOLVENTES EM SÍNTESE - O WORKUP COMO EXEMPLO
}

\author{
José Ricardo M. Pinto $\#$, , Maria Gabriela T. C. Ribeiro*,\#, ${ }^{*, 1}$ e Adélio A. S. C. Machado \\ a'Departamento de Química e Bioquímica, Faculdade de Ciências da Universidade do Porto, Rua do Campo Alegre 687, 4169-007 \\ Porto, Portugal
}

Recebido em 19/05/2019; aceito em 15/07/2019; publicado na web em 26/08/2019

\begin{abstract}
THE SOLVENT CHALLENGE IN SYNTHESIS - THE WORKUP AS EXAMPLE. A procedure for the assessment and optimization of the greenness of solvents in synthesis was developed. It involves two optimization components, aiming at the optimization of both the intrinsic greenness of the solvents and their efficiency to improve the overall green performance of the synthesis, evaluated with mass, energy and time greenness metrics. The procedure was tested in a study with educational purpose for assessing and improving the greenness of solvents used in the workup step of a ionic liquid synthesis that involves a solventless reaction step (1-hexyl-3methylimidazolium chloride) and proved useful to systematize the aspects that should be considered to choose the solvents used in the workup. The results show that there may be a competition in the solvent choice between a safer solvent and a more hazardous solvent with better performance of the overall synthesis process, which requires optimization for reaching a balanced solution. The study illustrates the problems of the substitution of solvents in synthetic processes to improve greenness, as well as the importance of the utilization of a battery of greenness metrics for evaluation of the overall synthesis outcomes.
\end{abstract}

Keywords: green chemistry; green chemistry education; synthesis solvents; greenness improvement; green metrics

\section{INTRODUÇÃO}

Os solventes têm merecido atenção diversificada em diferentes áreas da Química porque são utilizados nesta para os mais diversos fins, pelo que o seu estudo envolve vários aspetos, mesmo quando se considera apenas o respetivo uso em síntese. ${ }^{1,2}$ Essa atenção ampliou-se ainda mais com o desenvolvimento da Química Verde (QV), já que esta implica uma importância acrescida dos impactos ambientais variados dos solventes sobre o ambiente e saúde humana, incentivando investigação em áreas vigentes ou novas. ${ }^{3-6}$ Por exemplo, os processos e critérios de seleção de solventes têm de integrar novas dimensões referentes à verdura química e surgiu uma nova área dedicada ao design de solventes verdes e validação da respetiva verdura.

Na realidade, os solventes são um dos campos da QV onde se regista maior atividade de investigação e foi atingida uma implementação industrial mais eficaz, em especial na indústria farmacêutica (ver adiante). Esse desenvolvimento foi refletido no ensino laboratorial da $\mathrm{QV}$, surgindo propostas de revisão de procedimentos vigentes e de novos procedimentos para obter maior verdura em diversos campos em que se utilizam solventes ${ }^{5,6}$ (respetivamente Cap 6, p. 133 e Cap 12, p. 305), em especial no da síntese orgânica. ${ }^{7}$ A revisão dessa literatura mostrou que as abordagens educacionais, focadas na melhoria da verdura por substituição de solventes (ver detalhes adiante), consideravam apenas a perigosidade, saúde ocupacional e impactos ambientais desses, ignorando invariavelmente o efeito colateral da substituição sobre a verdura química global da síntese; por outro lado, as melhorias de verdura obtidas pela substituição não foram confirmadas por utilização de métricas de verdura para aferição quantitativa. Essa situação sugeriu que, no âmbito do ensino da QV, se desenvolvesse trabalho para abordar a tarefa da seleção ou substituição de solventes em síntese verde com visão holística, atendendo às diversas dimensões da verdura e avaliando-a por meio de métricas tão exaustivamente quanto possível.

*e-mail: gribeiro@fc.up.pt

"LAQV - Requimte
Nesse contexto, o objetivo geral do presente trabalho foi o desenvolvimento de procedimentos para a seleção de solventes nos processos de síntese e sua validação por via experimental, para um exemplo de síntese implementável em laboratório educacional. Esse objetivo geral envolveu dois objetivos específicos: primeiro, a inclusão na avaliação dos efeitos secundários do solvente na verdura química global do processo de síntese e não apenas dos efeitos ambientais do solvente; segundo, a seleção de um conjunto adequado de métricas de verdura ("bateria de métricas") para aferição eficaz da influência do solvente em várias dimensões da verdura do processo. Por outro lado, como a influência do workup na verdura da síntese, um aspeto frequentemente não contemplado na literatura educacional (e não só), tem merecido recentemente muita atenção (ver adiante), foi decidido incluir também a sua análise como terceiro objetivo específico do trabalho.

Para cumprir esses objetivos, este artigo foi organizado em sete secções, sendo esta introdução a primeira. Na segunda, inclui-se um breve panorama sobre o tema "Solventes e síntese verde", com vista a enquadrar o trabalho. Na terceira secção, analisa-se a complexidade da avaliação global dos solventes em síntese verde, com vista a conceber procedimentos de aferição da sua escolha de raiz e de substituições. A quarta descreve o trabalho experimental e a quinta os resultados e sua discussão. Na sexta secção apontam-se estratégias para o uso das conclusões do estudo nos laboratórios de ensino da QV. Finalmente, na última secção sumarizam-se globalmente os resultados obtidos.

\section{SOLVENTES E SÍNTESE VERDE}

Os papéis desempenhados pelos solventes na síntese química são variados, por exemplo, são empregados como meio da reação para facilitar as transferências de massa e de calor; e no isolamento e purificação do produto (o chamado workup) ${ }^{8,9}$ etc. Em consequência, os solventes são usados em grandes quantidades e constituem a maior parte dos resíduos gerados pelos processos sintéticos, por exemplo, até $80 \%$ na indústria farmacêutica. ${ }^{10,11}$ Além disso, os solventes historicamente mais usados em síntese são compostos orgânicos voláteis que, frequentemente, envolvem perigos ambientais e de segurança 
laboratorial. ${ }^{12}$ Estes e outros problemas são numerosos e justificam grande parte do interesse que a $\mathrm{QV}$ tem dedicado ao uso dos solventes.

Anastas e Warner incluíram recomendações precaucionárias sobre o uso de solventes nos doze princípios da QV, ${ }^{13}$ quer explicitamente no quinto ("evitar solventes e auxiliares se possível; caso contrário, usar alternativas mais seguras"), quer implicitamente nos outros princípios também envolvidos na escolha de solventes para um processo de síntese que se pretende verde: o primeiro ("é melhor prevenir a formação de resíduos do que ter que tratá-los"); o terceiro ("sínteses menos perigosas"); e o décimo segundo ("química inerentemente mais segura quanto à prevenção de acidentes"). Essas variadas recomendações quanto à escolha de solventes implicam uma multiplicidade de objetivos na promoção da síntese verde, evidenciando a dificuldade da tarefa, resultante da natureza multidimensional da verdura. As variadas barreiras ao cumprimento das prescrições encontradas na prática da QV aumentam essa dificuldade. Quanto a essas, o caso do quinto princípio é exemplar, embora longe de ser único, pois evitar o uso solventes tem limitações: embora as sínteses realizadas sem solvente como meio de reação possam constituir alternativas mais verdes, em muitas situações nem sequer são exequíveis, por exemplo, quando a viscosidade dos reagentes é excessiva, a transferência de massa pode ser difícil ou o controle de temperatura deficiente. ${ }^{12}$ Além disso, os processos sintéticos com base em reações sem solvente requerem quase sempre solventes no workup.

Os solventes têm tido particular atenção na prática industrial da QV, em especial na indústria farmacêutica, já que a fabricação de compostos medicinais envolve frequentemente vias sintéticas longas e complexas, as quais requerem grandes quantidades de solventes para as sucessivas reações, separações e purificações. Esse uso intensivo tem constituído uma forte motivação para encontrar solventes mais verdes para os processos de síntese farmacêutica. ${ }^{14}$

\section{Aferição da verdura intrínseca dos solventes}

Neste contexto, vários tipos de esforços foram desenvolvidos pelas empresas farmacêuticas, e não só, para caracterizar e classificar os solventes de modo a facilitar a escolha das alternativas mais benignas. ${ }^{15-17} \mathrm{O}$ modo potencialmente mais eficaz para aferir o impacto ecológico dos solventes usados no processo de fabrico de um produto é constituído pelas ferramentas de avaliação do ciclo de vida, ${ }^{18}$ mas essas requerem um grande número de dados, nem sempre disponíveis, e despendem muito tempo. Por isso, foram concebidas alternativas mais simples de diversos tipos para avaliar a chamada verdura intrínseca dos solventes. A verdura intrínseca de uma substância é o inverso da perigosidade - o conjunto de perigos potenciais da substância, os chamados perigos SHE (abreviatura em inglês para designar os perigos atendendo aos três tipos dos seus impactos: segurança física, saúde humana e ambiente - S de Safety, $\mathrm{H}$ de Human Health, E de Environmental).

Os guias de seleção de solventes constituem um tipo de ferramentas desenvolvido na indústria farmacêutica por várias companhias: GlaxoSmithKline (GSK), ${ }^{19,20}$ Pfizer, ${ }^{21}$ Sanofi, ${ }^{22}$ e AstraZeneca; ${ }^{23}$ bem como pela ACS Green Chemistry Institute Pharmaceutical Roundtable ${ }^{24}$ e pela IMI-CHEM21, ${ }^{25-27}$ um consórcio público-privado europeu. ${ }^{28} \mathrm{O}$ objetivo desses guias é promover a utilização de solventes mais verdes naquela indústria, mediante identificação das características adversas de solventes em uso, o que pressiona a eliminação dos indesejáveis, e identificação de alternativas adequadas para a sua substituição. Uma comparação recente desses guias ${ }^{29}$ mostrou algumas discrepâncias nos resultados, que resultam de diferentes filosofias nos objetivos, procedimentos de avaliação, características incluídas, critérios de classificação, etc., usados na sua conceção pelas diferentes empresas. Essa comparação utilizou quatro níveis de perigo (recomendado/ problemático/perigoso/altamente perigoso). Só para 39\% dos 51 solventes estudados foi verificada concordância entre os diversos guias, verificando-se a ocorrência de divergências significativas em $8 \%$; nos $53 \%$ restantes foram encontradas apenas pequenas discordâncias entre alguns dos guias. Mais precisamente, o estudo não conseguiu atribuir uma ordenação clara de 17 solventes (33\%): 11 foram classificados como recomendados ou problemáticos e 6 problemáticos ou perigosos. O sucesso relativo da comparação mostra como é difícil avaliar os perigos/impactos SHE dos solventes, o que se deve principalmente ao número e variedade dos parâmetros em jogo na comparação. Essa situação é uma consequência da complexidade da caracterização de solventes, que envolve várias classes de propriedades de tipos muito diferentes - não apenas as associadas aos perigos SHE. Apesar das discrepâncias, explicadas em parte por essa complexidade, os guias têm permitido uma melhoria na verdura do uso de solventes na síntese farmacêutica. No entanto, os guias privilegiam a segurança, nem todos levando em conta o impacto dos solventes em outros aspetos do processo de síntese global. Por exemplo, a água é muitas vezes referida como o solvente verde por excelência, mas isso pode não se concretizar na prática, dependendo do modo da sua utilização no processo de síntese, ${ }^{20}$ p. ex., se for necessário evaporar o solvente para purificar o produto, a baixa volatilidade da água pode ser um problema - um solvente mais volátil permite obter valores mais baixos para a energia despendida na evaporação.

Outra linha seguida para otimizar a escolha de solventes para sínteses, incluindo a avaliação de seus impactos, produziu um grande número de procedimentos e ferramentas de diferentes tipos, por exemplo, ${ }^{3-4,30-32}$ cuja variedade é outro sintoma da complexidade do assunto. Muitas dessas ferramentas de avaliação são de utilização intrincada, portanto, inadequadas para utilização em laboratórios educacionais, a não ser eventualmente em níveis avançados. Por isso, neste estudo foram utilizadas duas ferramentas de aplicação simples: a ferramenta EHS, ${ }^{33}$ que é constituída por uma planilha de Excel $^{33,34}$ na qual são listados os perigos de 100 substâncias, a maioria solventes orgânicos, avaliados com base em três indicadores, um para cada aspeto do SHE; ${ }^{15}$ e a ferramenta SHE, concebida pelos autores deste trabalho, ${ }^{35} \mathrm{com}$ base em informação sobre os perigos potenciais recolhida nas SDS (Safety Data Sheets) dos solventes, que são pontuados conforme o nível de perigosidade e apresentados em gráficos que proporcionaram uma visão global dos mesmos.

Os processos de aferição da verdura dos solventes, com exceção de algumas das ferramentas mais recentes e de utilização complexa, por exemplo, ${ }^{31,32}$ consideram apenas as suas caraterísticas SHE e propriedades físicas que as condicionam, ignorando a sua adequabilidade para promover o processo de síntese, em particular as reações químicas que o constituem.

\section{Solventes no processo de síntese}

A substituição de solventes problemáticos por solventes mais verdes requer uma visão global sobre o processo de síntese e, devido à sua elevada complexidade, exige uma abordagem sistémica. ${ }^{30} \mathrm{~A}$ Figura 1 apresenta uma visão holística do processo de síntese que, embora simplificada, mostra a omnipresença dos solventes nas suas sucessivas etapas, a qual ocorre na maioria das sínteses. Os solventes interagem diretamente com os outros componentes do sistema e estas conexões dificultam os processos da respetiva seleção e substituição. A Figura 1 mostra que o processo de síntese, além da reação química, inclui no workup operações físicas de isolamento e purificação do produto que requerem frequentemente vários solventes. No entanto, a figura é simplista, já que diz respeito a processos de síntese simples, constituídos por uma única reação; frequentemente, esses processos são constituídos por várias reações em sucessão (via 


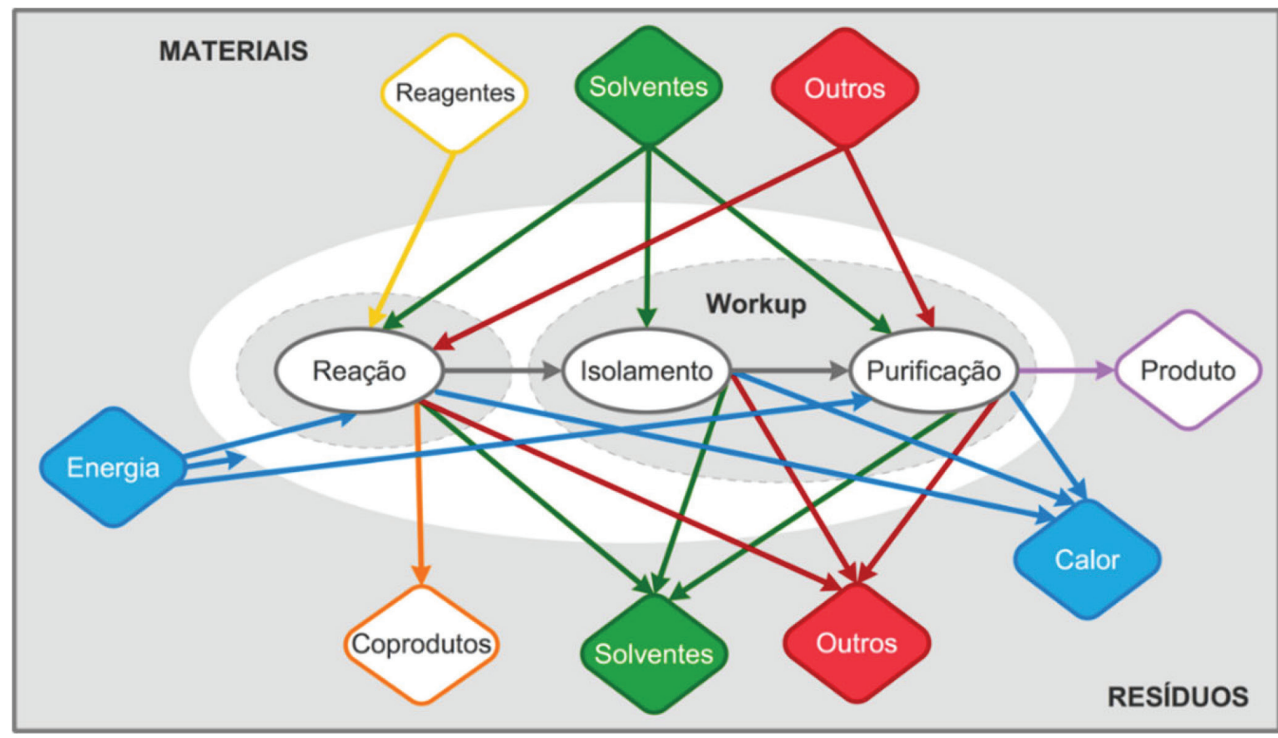

Figura 1. Sistema de um processo de síntese em geral (enfatizando a omnipresença dos solventes)

de síntese), valendo a figura, em princípio, para cada reação. Numa via de síntese pode haver interações entre as reações, resultantes de condicionalismos de uso de solventes específicos como meios reacionais nas diferentes reações, entre outros, o que implica acréscimo de complexidade.

\section{Solventes no ensino de síntese verde}

Na literatura de educação em QV só um número limitado de artigos se refere ao uso de solventes em experiências de síntese, propondo alternativas como reações sem solventes ${ }^{36-38}$ ou reações orgânicas em meio aquoso. ${ }^{36,39}$ Por exemplo, Dicks et al. ${ }^{38,39}$ discutem as vantagens de experiências sem solventes ${ }^{38}$ ou em meio aquoso ${ }^{39}$ nos laboratórios de ensino, realçando as vantagens da água sobre os solventes orgânicos, na perspetiva dos perigos SHE. A revisão desta literatura sobre modos de melhorar a verdura dos solventes usados em sínteses nos laboratórios de ensino mostra que nenhuma experiência foi proposta com o objetivo de consciencializar os estudantes para a complexidade do uso de solventes quando se pretende otimizar a verdura global do processo de síntese. As experiências de síntese que envolvem substituição de solventes ${ }^{36-37,39}$ propõem a realização da síntese em solventes mais verdes, mas comprovam apenas que a substituição não afeta a ocorrência da reação: não incluem comparações quanto à variação da verdura referente à química da reação de síntese, importantes para fazer sentir aos estudantes a necessidade de confirmar a otimização da verdura global e não apenas a dos solventes - já que a mudança de solvente pode deteriorar, por exemplo, a verdura de massa da reação.

Por outro lado, em trabalhos anteriores que visaram a otimização da verdura de sínteses muito simples, ${ }^{40}$ verificou-se que o workup poderia ser mais problemático para a verdura do que a reação, devido ao uso de solventes. Algumas das experiências pedagógicas de síntese, propostas na literatura com esta finalidade, centram-se apenas na verdura da fase de reação, subvalorizando o workup - e ignoram assim as limitações de verdura dos solventes usados neste. Por exemplo, Soares et al..$^{41}$ apresentam sínteses de dois derivados de 5-fenil-2-hidroxiacetofenona, referindo-as como mais verdes que as descritas na literatura, por usarem água como meio de reação e micro-ondas para o aquecimento. Contudo, ignoram os efeitos negativos do workup para a verdura devidos aos solventes: ${ }^{42}$ (1) filtração com celite; (2) extrações líquido-líquido com diclorometano; e (3) purificação por cromatografia, na qual se usa heptano e hexano.
Como os procedimentos do workup da síntese são essenciais para a obtenção do produto com pureza e rendimento aceitáveis, a sua verdura tem de ser aferida com cuidado. ${ }^{42}$ Por isso, em consequência da importância do workup em síntese, é necessário aprofundar conceitos e desenvolver competências para realizar esta fase sem deteriorar a verdura, ${ }^{43}$ o que é essencial para obter verdura no processo global de síntese. Aliás, essa atitude segue o conselho de Goodwin, ${ }^{44}$ que logo em 2004 sugeriu que, em todos os trabalhos laboratoriais, os estudantes devem ser questionados sobre os aspetos mais e menos verdes, e sobre formas de melhorar a verdura global do processo.

\section{A COMPLEXIDADE DA AVALIAÇÃO GLOBAL DOS EFEITOS DOS SOLVENTES NA VERDURA DAS SÍNTESES}

Dada a omnipresença de solventes nos processos de síntese (ver a Figura 1), a avaliação do modo como os solventes escolhidos influenciam a verdura do processo é complexa, já que frequentemente são usados vários solventes nas duas fases da síntese (reação e workup) para cumprimento de funções distintas. Além disso, o solvente usado na fase de reação como meio reacional influencia em muitos casos o mecanismo de avanço da reação e a qualidade do produto obtido. Em consequência, a avaliação global da verdura dos solventes em sínteses requer três avaliações paralelas, dirigidas a: (i) verdura intrínseca dos solventes, para obter a maior benignidade possível quanto aos aspetos SHE; (ii) implicações dos solventes na pureza do produto e rendimento da síntese; e (iii) efeitos dos solventes na verdura global do processo de síntese, avaliados por métricas de verdura (ver o esquema na Figura 2).

Quanto à primeira avaliação, a verdura intrínseca do solvente é independente do seu uso na síntese, dependendo apenas das propriedades caraterísticas do solvente, e pode ser avaliada com vários instrumentos, como já referido: guias de seleção de solventes, ${ }^{19-27}$ a ferramenta EHS, ${ }^{33}$ ou a ferramenta SHE. ${ }^{35}$ A escolha do instrumento depende do contexto, por exemplo, no ensino a níveis pré-universitários pode ser utilizada a ferramenta SHE, mais simples, mas a níveis superiores podem ser também utilizados os guias de seleção de solventes e a ferramenta EHS.

Apesar da verdura intrínseca dos solventes ser um aspeto importante para avaliar a segurança e o impacto ambiental resultante da sua utilização, para aferir a verdura global de um solvente num processo de síntese é também necessário ter em conta dois aspetos do seu comportamento: primeiro, a influência do solvente na eficiência 


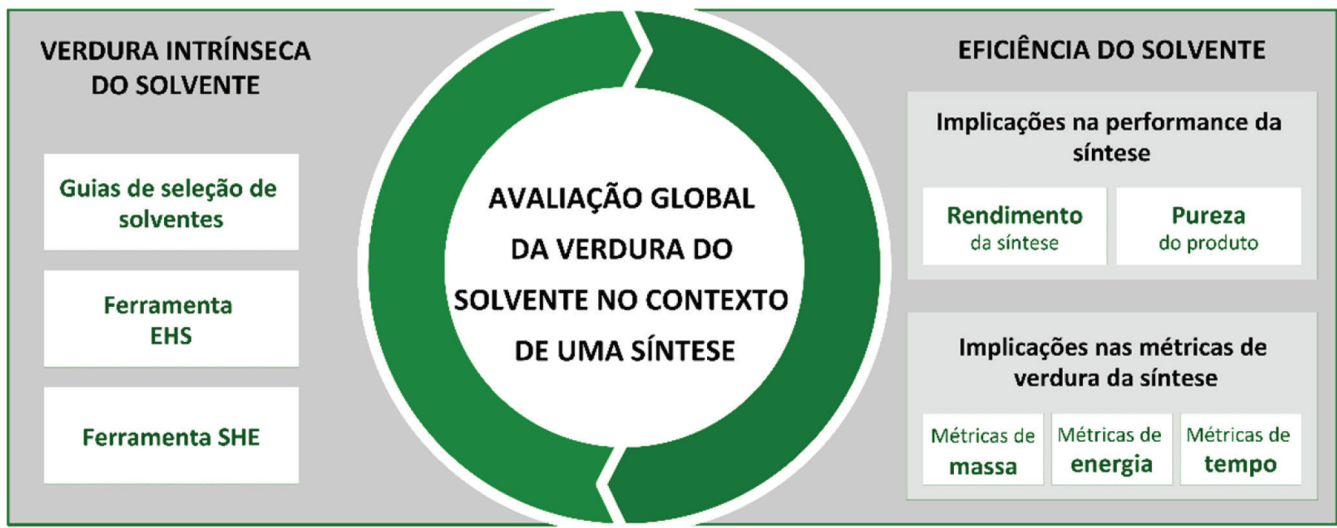

Figura 2. Avaliação da verdura de solventes usados em sínteses

do processo, isso é, se possibilita a obtenção do produto com elevado rendimento e qualidade; e, segundo, o impacto do solvente na verdura global do processo, isso é, se suporta a implementação de um processo verde, apreciado por métricas de verdura. Assim, são requeridas duas componentes de avaliação dirigidas ao cumprimento desses dois objetivos: uma dirigida à eficiência do solvente, que depende do impacto do seu uso na performance da síntese (aferida pelos valores do rendimento e pureza do produto obtido); e outra referente à verdura da síntese (avaliada pelos valores das métricas de uma bateria que permite a aferição de várias componentes da verdura). Essas duas avaliações paralelas dos efeitos do solvente no processo previnem danos colaterais do uso de solventes escolhidos por serem intrinsecamente benignos, já que um solvente escolhido por ser menos perigoso pode conduzir a um produto final contaminado com impurezas, incluindo resíduos do próprio solvente, e/ou implicar deterioração da verdura global do processo.

Por isso, avaliar a eficiência do solvente, para além do cálculo do rendimento e do estudo da pureza, requer o cálculo de métricas de verdura para o processo de síntese global, com o fim de aferir aspetos da síntese influenciados diretamente pelo uso de solventes. ${ }^{45-49}$ Por exemplo, para suportar comparações quando solventes alternativos são experimentados numa síntese com vista a otimizar a sua verdura, o bom aproveitamento dos átomos dos reagentes e a quantidade de resíduos produzidos devem ser avaliados por métricas de massa específicas.

\section{Bateria de métricas}

A bateria de métricas utilizada neste trabalho fornece informação separada sobre as verduras mássica, energética e de tempo do processo de síntese, bem como sobre as contribuições das diferentes componentes da verdura mássica (no uso dos solventes, no caso presente), proporcionando uma visão holística da verdura do processo. No quadro de pensamento sistémico, uma bateria de métricas é um conjunto de métricas que funcionam como um todo, constituindo um sistema de avaliação que, acoplado ao sistema em estudo, permite obter informação sobre ele; as métricas da bateria são criteriosamente escolhidas para captar informação sobre as variáveis do sistema que influenciam o seu funcionamento, sendo por isso relevantes para a gestão do sistema. ${ }^{45-49} \mathrm{O}$ conjunto de métricas selecionadas para constituir o sistema de avaliação varia o com problema em análise, conforme a informação que se pretende captar.

A bateria de métricas usada no caso presente, além das métricas de massa "clássicas" para o processo de síntese global (AE, RME e $\mathrm{MI})$, inclui também métricas de energia (EI) $)^{50-53} \mathrm{e}$ de tempo (TI ${ }^{51,52}$ (Tabela 1). A medição de energia utilizada na síntese laboratorial (raramente é incluída em experiências de síntese, ${ }^{50-53}$ sendo normalmente negligenciada em laboratório, mas permite o cálculo de métricas de energia para avaliações da verdura energética; além disso, permite aos estudantes tomar consciência da importância desta variável na atividade industrial da química. ${ }^{51,52}$

Tabela 1. Métricas de verdura e respetivas fórmulas de cálculo ${ }^{\alpha}$

\begin{tabular}{lcc}
\hline Abreviatura & Métrica & Fórmula \\
\hline AE & Economia atómica & $\mathrm{AE}=100\left(\frac{\mathrm{p} \cdot \mathrm{MM}_{\mathrm{P}}}{\mathrm{a} \cdot \mathrm{MM}_{\mathrm{A}}+\mathrm{b} \cdot \mathrm{M} \mathrm{M}_{\mathrm{B}}}\right)$ \\
RME & $\begin{array}{c}\text { Eficiência de massa da } \\
\text { reação }\end{array}$ & $\mathrm{RME}=100\left(\frac{\mathrm{m}_{\mathrm{P}}}{\mathrm{m}_{\mathrm{A}}+\mathrm{m}_{\mathrm{B}}}\right)$ \\
$\mathrm{MI}$ & $\begin{array}{l}\text { Intensidade de massa } \\
\text { EI }\end{array}$ & $\mathrm{MI}=\frac{\mathrm{m}_{\mathrm{A}}+\mathrm{m}_{\mathrm{B}}+\mathrm{m}_{\mathrm{s}}+\mathrm{m}_{\text {aux }}}{\mathrm{m}_{\mathrm{P}}}$ \\
Intensidade de energia & $\mathrm{EI}=\frac{\mathrm{E}}{\mathrm{m}_{\mathrm{P}}}=\frac{\mathrm{E}(\mathrm{RS})+\mathrm{E}(\mathrm{WS})}{\mathrm{m}_{\mathrm{P}}}$ \\
& Intensidade de tempo & $\mathrm{TI}=\frac{\mathrm{t}}{\mathrm{m}_{\mathrm{P}}}=\frac{\mathrm{t}(\mathrm{RS})+\mathrm{t}(\mathrm{WS})}{\mathrm{m}_{\mathrm{P}}}$
\end{tabular}

$\overline{{ }^{\alpha} \text { Equação química: } \mathrm{aA}+\mathrm{bB} \rightarrow \mathrm{pP}+\mathrm{cD} ; a, b, c, p-\text { coeficientes estequio- }}$ métricos; $m_{\mathrm{A}}$ e $m_{\mathrm{B}}-$ massas dos reagentes estequiométricos; $m_{\mathrm{P}}-$ massa do produto; $m_{\mathrm{S}}-$ massa de solventes usados na síntese; $\mathrm{MM}_{\mathrm{A}}, \mathrm{MM}_{\mathrm{B}}$ e $\mathrm{MM}_{\mathrm{P}}$ - massas molares dos reagentes estequiométricos e do produto; $\mathrm{E}$ - energia usada na síntese; E(RS) - energia usada na fase de reação da síntese; E(WS) - energia usada na fase de workup da síntese; $t$ - tempo usado na síntese; $t(\mathrm{RS})$ - tempo usado na fase de reação da síntese; $t$ (WS) - tempo usado na fase de workup da síntese.

As métricas MI, EI e TI são normalizadas para o produto, i. e., calculadas como uma razão para a unidade de massa do produto (denominador), em que o numerador é uma soma de parcelas (de massas, energias ou tempo) que se referem separadamente às duas fase do processo global; portanto, podem ser parceladas para a reação e o workup, por exemplo, MI = MI(RS) + MI(WS), em que RS e WS resultam das designações inglesas "reaction step" e "workup step" ${ }_{54}$ Essas métricas parcelares proporcionam informação sobre o contributo das massas, da energia e do tempo envolvidos em cada fase, para o valor global da métrica respetiva e, portanto, na verdura global. Para as métricas de massa, pode fazer-se também uma outra parcelização para calcular métricas que descriminem solventes e reagentes e forneçam informação detalhada sobre o modo como as respetivas massas afetam a verdura mássica global, por exemplo, MI = SI + ReagI, em que SI se refere aos solventes e ReagI aos reagentes estequiométricos e a todos os reagentes auxiliares não solventes. Na Tabela 2 listam-se as métricas parcelares usadas neste trabalho e na Figura 3 apresenta-se uma visão 
Tabela 2. Métricas parcelares de verdura e respetivas fórmulas de cálculo ${ }^{\alpha}$

\begin{tabular}{|c|c|c|}
\hline Abreviatura & Métrica & Fórmula \\
\hline MI(RS) & MI parcelar para a reação & $\operatorname{MI}(\mathrm{RS})=\frac{\mathrm{m}_{\mathrm{A}}+\mathrm{m}_{\mathrm{B}}+\mathrm{m}_{\mathrm{s}}(\mathrm{RS})+\mathrm{m}_{\text {aux }}(\mathrm{RS})}{\mathrm{m}_{\mathrm{P}}}$ \\
\hline MI(WS) & MI parcelar para o workup & $\mathrm{MI}(\mathrm{WS})=\frac{\mathrm{m}_{\mathrm{s}}(\mathrm{WS})+\mathrm{m}_{\mathrm{aux}}(\mathrm{WS})}{\mathrm{m}_{\mathrm{P}}}$ \\
\hline SI & MI parcelar para os solventes & $\mathrm{SI}=\frac{\mathrm{m}_{\mathrm{S}}}{\mathrm{m}_{\mathrm{P}}}=\frac{\mathrm{m}_{\mathrm{s}}(\mathrm{RS})+\mathrm{m}_{\mathrm{s}}(\mathrm{WS})}{\mathrm{m}_{\mathrm{P}}}$ \\
\hline ReagI & MI parcelar para os reagentes não solventes & ReagI $=\frac{\mathrm{m}_{\mathrm{A}}+\mathrm{m}_{\mathrm{B}}+\mathrm{m}_{\text {aux }}(\mathrm{RS})+\mathrm{m}_{\text {aux }}(\mathrm{WS})}{\mathrm{m}_{\mathrm{P}}}$ \\
\hline $\mathrm{EI}(\mathrm{RS})$ & EI parcelar para a reação & $\mathrm{EI}(\mathrm{RS})=\frac{\mathrm{E}(\mathrm{RS})}{\mathrm{m}_{\mathrm{P}}}$ \\
\hline $\mathrm{EI}(\mathrm{WS})$ & EI parcelar para o workup & $\mathrm{EI}(\mathrm{WS})=\frac{\mathrm{E}(\mathrm{WS})}{\mathrm{m}_{\mathrm{P}}}$ \\
\hline $\mathrm{TI}(\mathrm{RS})$ & TI parcelar para a reação & $\mathrm{TI}(\mathrm{RS})=\frac{\mathrm{t}(\mathrm{RS})}{\mathrm{m}_{\mathrm{P}}}$ \\
\hline TI(WS) & TI parcelar para o workup & $\mathrm{TI}(\mathrm{WS})=\frac{\mathrm{t}(\mathrm{WS})}{\mathrm{m}_{\mathrm{P}}}$ \\
\hline
\end{tabular}

${ }^{\alpha} m_{\mathrm{A}}$ e $m_{\mathrm{B}}-$ massas dos reagentes estequiométricos; $m_{\mathrm{P}}-$ massa do produto; $m_{\mathrm{S}}-$ massa de solventes usados na síntese; $m_{\mathrm{S}}(\mathrm{RS})$ - massa de solventes usados na fase de reação; $m_{\mathrm{S}}$ (WS) - massa de solventes usados na fase de workup; $m_{\text {aux }}(\mathrm{RS})$ - massa de outras substâncias auxiliares usadas na fase de reação; $m_{\text {aux }}($ WS $)$ - massa de outras substâncias auxiliares usadas na fase de workup; E(RS) - energia usada na fase de reação da síntese; E(WS) - energia usada na fase de workup da síntese; $t(\mathrm{RS})$ - tempo usado na fase de reação da síntese; $t(\mathrm{WS})$ - tempo usado na fase de workup da síntese.

global da utilização da bateria de métricas descrita, constituída por métricas globais e parcelares, que mostra como obter uma descrição detalhada das verduras de massa e de energia, bem como da utilização do tempo, para o processo de síntese. Esta figura é suplementada pela
Figura 22S do Material Suplementar, em que se apresentam esquemas das relações entre as métricas usadas para o caso particular da síntese realizada neste trabalho, em que na fase de reação não se usaram solventes (ver adiante).

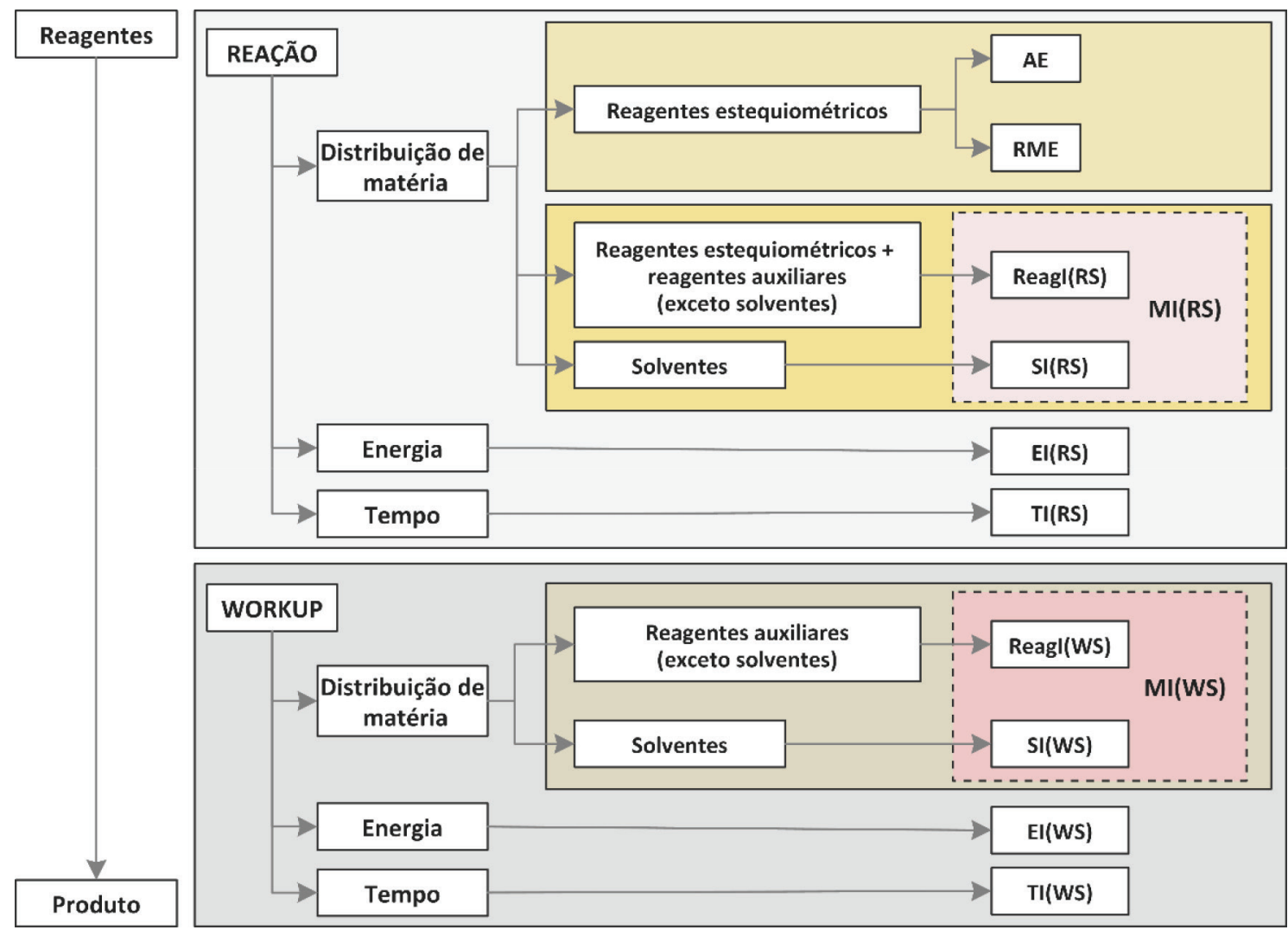

Figura 3. Distribuição da matéria, da energia e do tempo, nas fases de reação (RS) e de workup (WS) 
A descrição completa dos fluxos de materiais e de energia permite conhecer a utilização da matéria e da energia ao longo do processo de síntese, suportando o cálculo das métricas. Para esse fim, é requerido o registo detalhado, ao longo da execução da síntese, das quantidades de substâncias usadas, não só dos reagentes estequiométricos, mas também dos solventes e de outros materiais auxiliares.

\section{PARTE EXPERIMENTAL}

\section{Planificação do trabalho experimental}

Em face da finalidade educacional do trabalho, procurou-se uma síntese que cumprisse os seguintes critérios: (i) ser suficientemente simples para poder ser realizada em aulas práticas de tempo limitado; (ii) possibilitar um design exequível, sem demasiada complicação, da substituição de solventes para otimização da verdura do processo de síntese; e (iii) permitir a aferição dos resultados em várias dimensões da verdura, mediante uma bateria de métricas adequada para captar as respetivas variações. Uma pesquisa no Journal of Chemical Education revelou que identificar sínteses que cumprissem estes requisitos não era tarefa fácil, tendo-se optado pela síntese de um líquido iónico (LI) derivado do 1-hexil-3-metilimidazol ( $\left.\mathrm{C}_{6} \mathrm{MIM}\right){ }^{54}$ Essa referência descreve a síntese de dois LI semelhantes, o cloreto de 1-hexil-3-metilimidazol ([ $\left.\left.\mathrm{C}_{6} \mathrm{MIM}\right] \mathrm{Cl}\right)$, e o brometo de 1-hexil-3-metilimidazol ([ $\left.\left.\mathrm{C}_{6} \mathrm{MIM}\right] \mathrm{Br}\right)$, que requerem o uso de solventes apenas na fase de workup, o que simplifica as experiências quanto à substituição desses. Após comparação das duas sínteses, optou-se pela do $\left[\mathrm{C}_{6} \mathrm{MIM}\right] \mathrm{Cl}$ por ser: (i) a opção mais verde segundo a avaliação com métricas de massa realizada pelos autores; (ii) a síntese menos perigosa porque se usa o reagente clorohexano, sem indicações de perigo para a saúde humana, enquanto que a síntese do $\left[\mathrm{C}_{6} \mathrm{MIM}\right] \mathrm{Br}$ implica o uso de bromohexano, perigoso para a saúde (códigos de perigo H315, H319, H335); e (iii) a síntese na qual foi obtido maior rendimento (com um tempo de reação de 6 horas).

\section{Reação de síntese do cloreto de 1-hexil-3-metilimidazol}

$\mathrm{O}$ LI [ $\left.\mathrm{C}_{6} \mathrm{MIM}\right] \mathrm{Cl}$ foi obtido por reação entre o 1-MIM e o 1-clorohexano, 1-ClHex, em um passo ${ }^{55}$ (Figura 4). A fase de reação, realizada sem solvente como meio, foi seguida de workup para eliminação dos reagentes que remanesceram sem reagir, por extração com solvente, seguida de secagem do produto em evaporador rotativo. Na extração foram utilizados os solventes água, éter dietílico e acetato de etilo, em três protocolos sucessivos (A-C). O protocolo A, da literatura, ${ }^{54}$ envolvia o uso de uma mistura de água e éter dietílico, mas a utilização da água foi problemática: verificou-se ser difícil remover completamente a água do produto obtido, por evaporação, o que diminuiu o seu grau de pureza (ver adiante detalhes sobre o protocolo A). Por isso, no protocolo B excluiu-se a água, sendo o éter dietílico o único solvente usado. Como a utilização deste solvente envolve problemas de segurança, devido aos seus elevados perigos, foi substituído no protocolo $\mathrm{C}$ por outro menos perigoso, o acetato de etilo, considerando mais adequado para o contexto dos laboratórios de ensino.

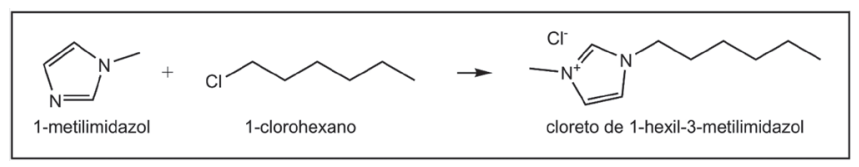

Figura 4. Esquema de síntese do $\left[\mathrm{C}_{6} \mathrm{MIM}\right] \mathrm{Cl}$

A quantidade de energia elétrica usada e o tempo utilizado, quer para a reação (foi utilizada uma manta de aquecimento com agitação magnética), quer para o workup (usou-se um evaporador rotativo com uma bomba de vácuo e um sistema de refrigeração), foram medidos em todas as experiências com um aparelho PeakTech 2510. A pureza do produto obtido pelos protocolos $\mathrm{B}$ e $\mathrm{C}$ foi avaliada por ${ }^{1} \mathrm{H}$ RMN. Os resultados mostram que a pureza das amostras obtidas por ambos esses protocolos foi elevada e semelhante. Os espetros obtidos foram ainda comparados com o espetro de uma amostra comercial do LI obtida da Sigma-Aldrich (ref. 87929), que mostrou que a pureza dos produtos obtidos pelos protocolos B e C é similar à dessa amostra.

Um roadmap com os principais detalhes da estratégia seguida no trabalho experimental é apresentado no Material Suplementar, bem como os pormenores dos protocolos, apresentando-se a seguir apenas alguns comentários sobre as substituições de solventes.

Protocolo A - Nesse protocolo ${ }^{54}$ a remoção completa da água do produto mostrou-se difícil: após 6 horas no evaporador rotativo, 13 g de água, ou $65 \%$ da água adicionada (20 g), ainda permaneciam em 41 g de LI final bruto. Como aumentar o tempo de evaporação iria piorar as métricas de energia, a água não pode ser considerada um solvente eficiente para o processo da síntese, pelo que se decidiu eliminar o seu uso no protocolo B.

Protocolo B - Na ausência de água, a viscosidade do produto bruto aumentou, mas obteve-se um produto de maior pureza (ver espetros de ${ }^{1} \mathrm{H}$ RMN, Material Suplementar, Figuras 8S, 11S, 12S e $15 \mathrm{~S})$. O tempo e a energia usados no evaporador rotativo diminuíram acentuadamente em relação ao protocolo A (6 h para 12 min e 4500 Wh para $81 \mathrm{Wh}$, respetivamente). No entanto, o uso de éter dietílico é inseguro, devido à sua elevada volatilidade e perigos para a saúde, pelo que se decidiu substituí-lo por uma alternativa mais benigna no protocolo $\mathrm{C}$.

Protocolo C - Após análise de perigosidade dos solventes através de guias de seleção e das ferramentas EHS e SHE (ver seção seguinte), optou-se pelo acetato de etilo. A pureza do produto manteve-se elevada (ver espetros de ${ }^{1} \mathrm{H}$ RMN, Material Suplementar, Figuras 9S, $11 \mathrm{~S}, 3 \mathrm{~S}$ e $15 \mathrm{~S}$ ), mas a energia e o tempo utilizados no evaporador rotativo aumentaram, porque o acetato de etilo é menos volátil que o éter dietílico (p.e. $77^{\circ} \mathrm{C}$ vs. $34,6^{\circ} \mathrm{C}$, respetivamente).

\section{RESULTADOS E DISCUSSÃO}

Os resultados da avaliação da influência da substituição dos solventes no workup da síntese de $\left[\mathrm{C}_{6} \mathrm{MIM}\right] \mathrm{Cl}$ são apresentados a seguir, sucessivamente para as suas três componentes.

\section{Avaliação da verdura intrínseca dos solventes}

A verdura intrínseca dos solventes foi avaliada com guias de seleção de solventes ${ }^{19-27}$ e com as ferramentas EHS ${ }^{33}$ e SHE. ${ }^{35}$ A água não foi incluída na avaliação por ser uma substância inócua.

\section{Guias de seleção de solventes}

A avaliação da verdura intrínseca dos solventes foi realizada com guias ${ }^{19-27}$ que incluem informação adequada para permitir a sua utilização (descriminados na Figura 5). Esses guias utilizam e fornecem informações de modos diferentes, o que limita as comparações dos resultados. Estes mostram que o éter dietílico é um solvente problemático, enquanto o acetato de etilo é considerado mais aceitável em todos as guias.

\section{Ferramenta EHS}

Essa ferramenta ${ }^{33}$ de avaliação de substâncias foi concebida para ser usada na identificação dos perigos nas etapas precoces do desenvolvimento de processos químicos. ${ }^{15,33}$ A ferramenta foi construída numa folha de cálculo Excel, ${ }^{15}$ a partir de informação recolhida de 


\begin{tabular}{|l|c|c|c|c|}
\hline Solventes & Pfizer $^{21}$ & GlaxoSmithKline & Sanofi & CHEM21 $^{25}$ \\
\hline Éter dietílico & Indesejável & Solventes muito perigosos & Banido & Muito perigoso \\
\hline Acetato de etilo & Preferido & Solventes pouco perigosos & Recomendado & Recomendado \\
\hline
\end{tabular}

Figura 5. Comparação da avaliação dos solventes por diferentes guias de seleção

várias bases de dados acerca dos perigos das substâncias, cerca de cem, principalmente solventes orgânicos. Essas são avaliadas mediante três indicadores, um por cada componente SHE, ${ }^{15}$ com base em nove categorias, três para cada componente..$^{153} \mathrm{~A}$ cada categoria são atribuídas pontuações com valores entre 0 e 1; a pontuação de cada indicador SHE é a soma da pontuação das respetivas categorias, um valor entre 0 e 3 . A pontuação global é obtida por soma das pontuações dos três indicadores SHE, tendo um valor entre 0 e 9 . Em todas essas pontuações, o valor é tanto mais elevado quanto mais perigosa for a substância. Os resultados são apresentados numa tabela detalhada com as pontuações atribuídas a cada categoria e componente.

Os resultados da comparação dos solventes alternativos éter dietílico e acetato de etilo, apresentados na Figura 6, sugerem que o acetato de etilo é menos perigoso que o éter dietílico, confirmando a informação recolhida nos guias de solvente, mas com mais detalhes sobre os perigos. No que respeita à segurança física (Figura 6A), a principal diferença é a pontuação para a categoria reação/decomposição, onde o éter dietílico tem maior pontuação que o acetato de etilo (0,60 vs. 0,00$)$. Contudo, o acetato de etilo é mais perigoso para a saúde humana, principalmente devido à elevada pontuação na categoria irritação dérmica e ocular ${ }^{33}(0,63$ vs. 0,00$)$; as pontuações para as outras duas categorias (toxicidade aguda e toxicidade crónica) são semelhantes (Figura 6B). A pontuação mais elevada para o ambiente foi encontrada para o éter dietílico, devido às pontuações para a persistência $(0,74)$ e perigo de contaminação da água $(0,13)$, superiores às do acetato de etilo (Figura 6C). Os resultados globais (Figura 6D) evidenciam que o éter dietílico tem pontuações mais

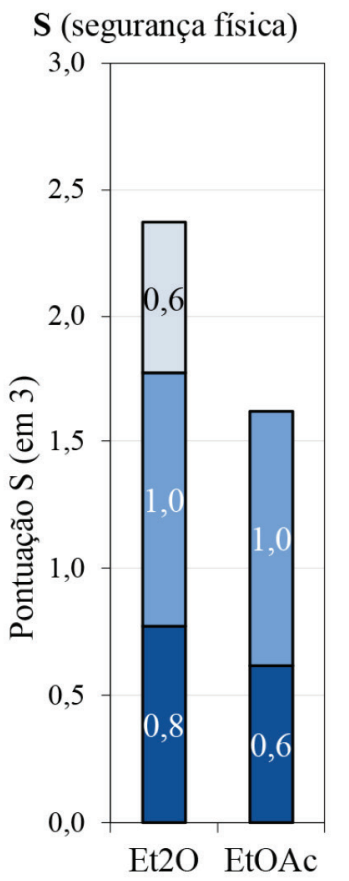

$\square$ Reação/decomposição
IIncêndio/explosão
$\square$ Potencial de dispersão

(A)

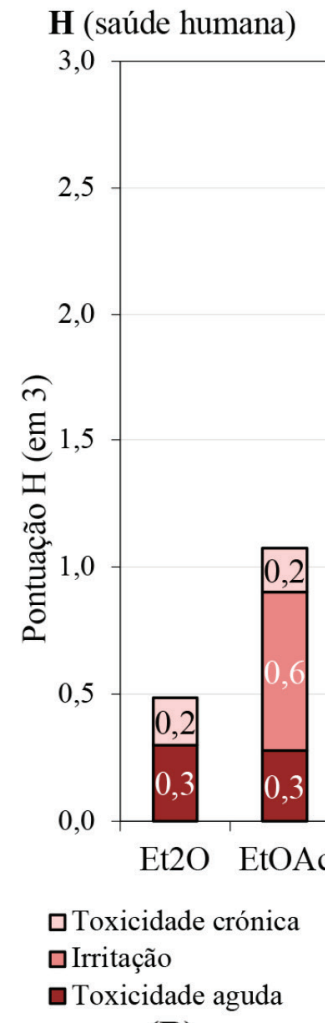

(B)

elevadas quanto à perigosidade física $(2,37$ vs. 1,62$)$ e ao ambiente $(1,0$ vs. 0,2$)$, mas é vantajoso quanto à saúde humana ( 0,5 vs. 1,1$)$.

Em suma, os dados da avaliação com a ferramenta EHS confirmam a vantagem do acetato de etilo, cuja pontuação global é $35 \%$ mais elevada (2,90 vs. 3,90 para o éter dietílico), embora a vantagem pareça ser menos nítida do que a obtida com os guias de solventes, todos também mais favoráveis ao acetato de etilo (ver Figura 5). No entanto, essa comparação é problemática, porque as avaliações são de natureza diferente, semiquantitativa na ferramenta EHS e qualitativa nos guias; além disso, a diferente linguagem usada na classificação dos solventes nos diferentes guias acarreta ambiguidades.

\section{Ferramenta SHE}

Nessa ferramenta, ${ }^{35,56,57}$ os perigos das substâncias, obtidos das respetivas SDS, após pontuação numa escala de 0 (perigo baixo) a 2 (perigo elevado), são apresentados em gráficos que permitam obter uma visão global dos mesmos.

Os resultados para os dois solventes são apresentados na Figura 7 (ver detalhes da construção nas referências 58 e 59). Os triângulos SHE (TSHE) são idênticos, sugerindo que as perigosidades globais são aproximadamente do mesmo nível. Os espetros de perigos potenciais (EPP), porém, apresentam diferenças, embora alguns se repitam em ambos (H336, EUH066): ocorre uma diferença nas inflamabilidades (o H224 do éter dietílico é mais penalizante que o H225 do acetato de etilo), mas não é captada pela ferramenta devido a falta de sensibilidade da escala de pontuação; e o éter dietílico apresenta mais um perigo físico elevado (EUH019). Esses resultados mostram que o

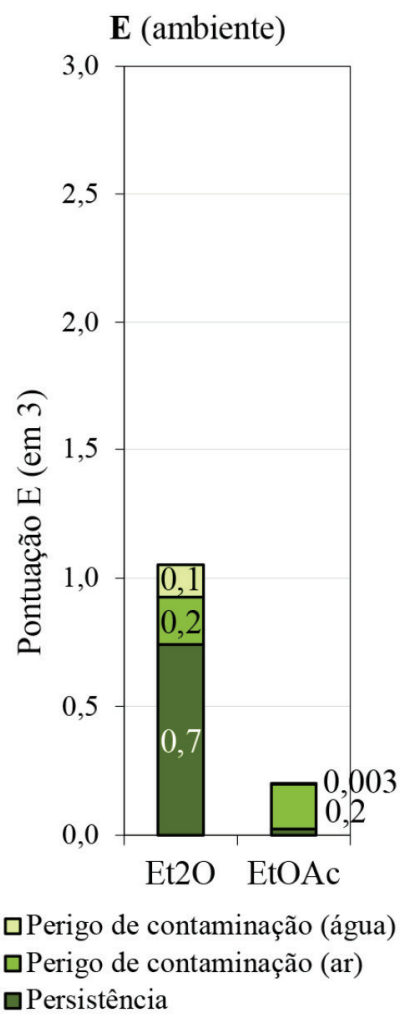

(C)

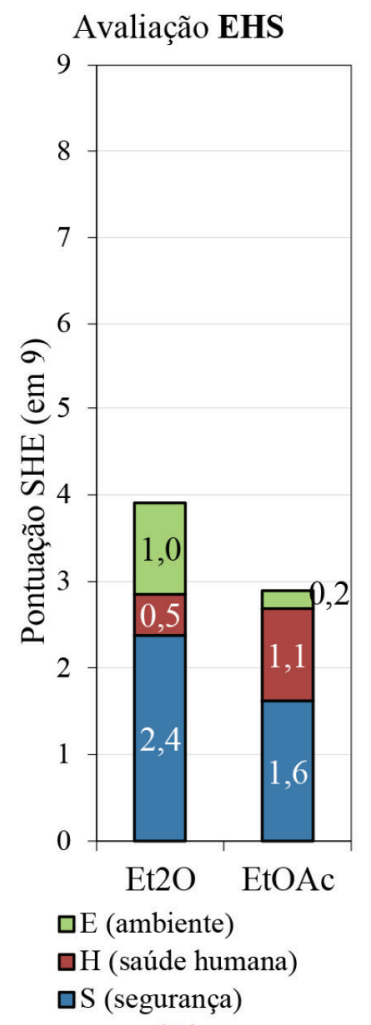

(D)

Figura 6. Resultados da avaliação da perigosidade dos solventes éter dietílico (Et2O) e acetato de etilo (EtOAc) com a ferramenta EHS: (A) perigosidade física; (B) saúde humana; (C) ambiente e (D) global 


\begin{tabular}{|c|c|c|c|}
\hline Triângulos SHE (TSHE) & & Códigos e frases de perigo & $\begin{array}{l}\text { Espetros de perigos } \\
\text { potenciais (EPP) }\end{array}$ \\
\hline \multicolumn{4}{|l|}{ Éter dietílico } \\
\hline \multirow{5}{*}{ E } & $\mathrm{H} 224$ & Líquido e vapor extremamente inflamáveis & \multirow{5}{*}{$\begin{array}{l}2 \\
1\end{array}$} \\
\hline & EUH019 & Pode formar peróxidos explosivos & \\
\hline & $\mathrm{H} 302$ & Nocivo por ingestão & \\
\hline & H336 & Pode provocar sonolência ou vertigens & \\
\hline & EUH066 & $\begin{array}{l}\text { Pode provocar pele seca ou gretada por } \\
\text { exposição repetida }\end{array}$ & \\
\hline \multicolumn{4}{|l|}{ Acetato de etilo } \\
\hline \multirow{4}{*}{${ }_{2}^{H}$} & $\mathrm{H} 225$ & Líquido e vapor altamente inflamáveis & \\
\hline & H319 & Provoca irritação ocular grave & \\
\hline & H336 & Pode provocar sonolência ou vertigens & \\
\hline & EUH066 & $\begin{array}{l}\text { Pode provocar pele seca ou gretada por } \\
\text { exposição repetida }\end{array}$ & \\
\hline
\end{tabular}

Figura 7. Resultados da avaliação da perigosidade dos solventes com a ferramenta SHE

acetato de etilo é mais benigno do que o éter dietílico, confirmando os obtidos nas avaliações anteriores.

\section{Discussão sumativa das três avaliações}

Embora as três avaliações apontem para o mesmo resultado, com vantagem do acetato de etilo, a sua concordância não é absoluta, o que resulta da diferente natureza e/ou de detalhes nos critérios que usam, um aspeto que poderá servir para fazer sentir aos estudantes as dificuldades da tarefa de aferir os perigos potenciais das substâncias químicas, devido à sua complexidade.

\section{Avaliação do efeito dos solventes na performance e verdura da síntese}

Os valores dos rendimentos obtidos bem como das métricas de verdura de massa, energia e tempo, para as sínteses realizadas pelos protocolos B e C, são apresentadas na Tabela 3. Na última coluna apresentam-se as diferenças dos valores das métricas (em percentagem, relativamente a B), para facilitar a comparação.

Tabela 3. Valores das métricas de massa, energia e tempo

\begin{tabular}{lccc}
\hline Protocolo & $\mathrm{B}$ & $\mathrm{C}$ & $\mathrm{C}-\mathrm{B} / \%$ \\
\hline Rendimento / \% & 84,3 & $85,0 \pm 1,0$ & 0,8 \\
AE / \% & 100,0 & 100,0 & 0,0 \\
RME / \% & 83,8 & $84,8 \pm 0,8$ & 1,2 \\
MI = ReagI + SI & 5,12 & $6,15 \pm 0,06$ & 20,1 \\
SI= SI(WS) & 3,92 & $4,97 \pm 0,05$ & 26,8 \\
ReagI = ReagI(RS) & 1,19 & $1,18 \pm 0,1$ & $-0,84$ \\
EI / Wh g-1 & 7,9 & $9,4 \pm 0,4$ & 19 \\
TI / h g- & 0,171 & $0,177 \pm 0,007$ & $-0,6$ \\
\hline
\end{tabular}

Nota: $\mathrm{SI}=\mathrm{SI}(\mathrm{WS})+\mathrm{SI}(\mathrm{RS})=\mathrm{SI}(\mathrm{WS})$ porque $\mathrm{SI}(\mathrm{RS})=0$ (não foi usado solvente na fase de reação).

\section{Avaliação do efeito na performance}

Os rendimentos obtidos para as sínteses realizadas pelos protocolos B e C foram semelhantes, ca. 85\% (ver a Tabela 3), o que indica que a alteração do solvente não influenciou de forma significativa $o$ rendimento. Na síntese realizada segundo o protocolo $\mathrm{A}$, obteve-se uma mistura de $\left[\mathrm{C}_{6} \mathrm{MIM}\right] \mathrm{Cl}$ e água, ${ }^{55}$ tendo o produto final retido $65 \%$ da água adicionada, pelo que o rendimento e as métricas de verdura não foram calculadas, porque os valores não teriam significado.

Avaliação do efeito nas métricas de verdura

A reação de síntese nos protocolos $\mathrm{B}$ e $\mathrm{C}$ é a mesma e a sua $\mathrm{AE}$ é $100 \%$ porque todos os átomos dos reagentes estequiométricos são incluídos no produto (a reação não produz coprodutos). Os valores de RME para os protocolos B e C são similares, ca. $85 \%$, mostrando que essa métrica não foi afetada pela mudança de solvente, como era de esperar já que o respetivo cálculo não inclui as massas de solventes, só as massas de reagentes estequiométricos e do produto (Tabela 1). Como a reação foi realizada em proporções (quase) estequiométricas e as massas de reagentes estequiométricas usadas nos protocolos B e $\mathrm{C}$ foram semelhantes, a RME é diretamente proporcional à massa de produto obtida, logo ao rendimento; aliás, como a AE é $100 \%$, os valores da RME são praticamente iguais aos do rendimento. ${ }^{59}$ Os valores de RME são $15 \%$ inferiores ao máximo possível para a reação $(\mathrm{AE}=100 \%$, limite máximo para $\mathrm{RME})$, evidenciando uma perda moderada de átomos dos reagentes, semelhante em ambos os protocolos.

Para a avaliação da verdura global, foram calculadas as métricas de materialização (e perda de materiais em resíduos) MI e SI. A primeira é uma métrica de materialização global, ao passo que SI é a métrica parcelar de MI que afere a fração da materialização referente aos solventes. Essas métricas apresentam respetivamente valores de 5,12 e 3,92 para o protocolo B, e 6,15 e 4,97 para o protocolo C, indicando um nível de materialização baixo para o processo, o que resulta de não se usar solvente como meio da reação. A comparação dos valores das duas métricas mostra que SI, referente apenas a solventes usados no workup, é a maior parcela de MI. Contudo, os valores de MI e SI aumentam, respetivamente, $20 \%$ e $27 \%$, do protocolo B para $\mathrm{C}$.

Esse aumento pode ser explicado usando métricas parcelares para cada fase da síntese: MI foi dividida em duas parcelas, MI(RS) e MI(WS), relativas às fases de reação e workup, respetivamente. Os valores destas métricas são apresentados com os valores do SI na Figura 8A. A MI(WS) é igual à SI porque só são usados solventes no workup, sendo SI(RS) = 0. A variação na diferença SI - MI(RS), ou seja MI(WS) - MI(RS), entre os dois protocolos deve-se à utilização de solventes diferentes (éter dietílico em B e acetato de etilo em C). $\mathrm{O}$ volume de solvente usado foi o mesmo nos dois protocolos, sendo a variação explicada pela densidade mais elevada do acetato de etilo $(0,90)$ relativamente à do éter dietílico $(0,71)$. Pode concluir-se que, 


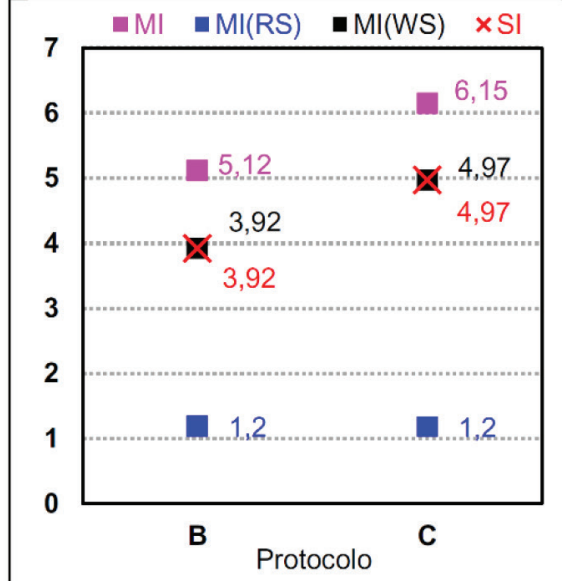

(A)

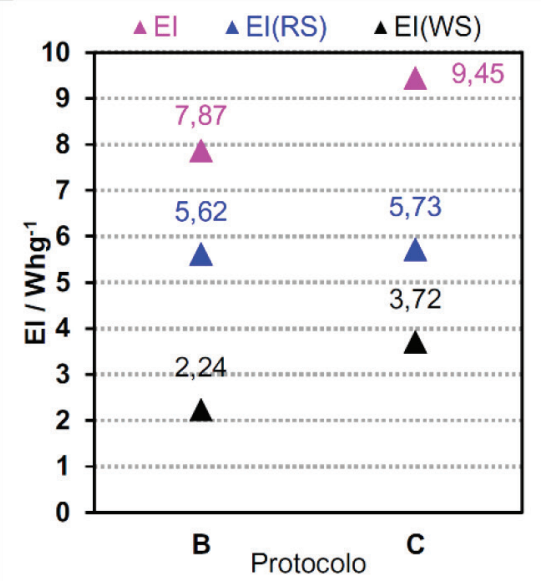

(B)

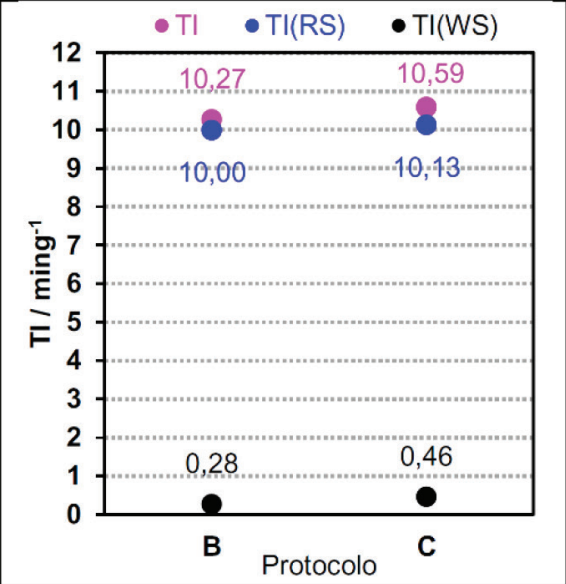

(C)

Figura 8. (A) Intensidades de massa para os protocolos B e C: processo global, MI, fases de reação, MI(RS) e de workup, MI(WS), e solventes, SI; (B) Intensidade de energia para os protocolos B e C: processo global, EI, fases de reação, EI(RS) e de workup, EI(WS) (C) Intensidade de tempo para os protocolos B e C: processo global, TI, fases de reação, TI(RS) e de workup, TI(WS)

como a MI é mais elevada para o protocolo $\mathrm{C}$, a opção mais verde em termos de materialização, ou seja, mais desmaterializada, é a que usa éter dietílico (protocolo B).

O cálculo das métricas de energia e de tempo permitiu investigar como os solventes afetam essas componentes da verdura e testar a consistência global na utilização das métricas. As métricas EI e a TI (Tabela 3) foram calculadas a partir dos resultados da medição das duas grandezas. Os valores de TI para os protocolos B e C são similares, mas o valor de EI aumenta $20 \%$ de B para C. Como a EI é maior no protocolo $\mathrm{C}$, a opção mais verde em termos de utilização de energia será o primeiro protocolo (solvente: éter dietílico), em concordância com o que foi discutido acima para os resultados das métricas de massa. O cálculo das métricas parcelares de energia e tempo para a reação e workup permite analisar mais aprofundadamente as contribuições individuais das duas etapas nas métricas e, em particular, explicar as diferenças nos valores de EI e TI para os dois protocolos, nomeadamente o aumento de $\mathrm{EI}$ de $\mathrm{B}$ para $\mathrm{C}$, enquanto TI se mantém. Os valores de EI(RS) e EI(WS) e de TI(RS) e TI(WS) são apresentados nas Figuras $8 \mathrm{~B}$ e $8 \mathrm{C}$, respetivamente.

As intensidades de energia e de tempo para a fase de reação (EI(RS) e TI(RS), respetivamente) foram semelhantes para ambos os protocolos (respetivamente, 5,62 e 5,73, ver Figura 8B; e 10,00 e 10,13, Figura 8C), o que está de acordo com o procedimento da fase de reação ser o mesmo e a alteração de solvente não ter efeito na sua eficiência, conforme discutido atrás na subsecção "Avaliação do efeito na performance." Contudo, para o workup, as intensidades de energia, EI(WS), e de tempo, TI(WS), foram maiores para o protocolo $\mathrm{C}$ do que para o protocolo $\mathrm{B}$ (respetivamente 3,72 e $2,24 \mathrm{Wh} \mathrm{g}^{-1}$ (ver a Figura 8B); e 0,28 e 0,46 min g $^{-1}$ Figura 8C). Isso é consequência da diferença de volatilidades dos solventes: como o acetato de etilo (protocolo C) é menos volátil que o éter dietílico (protocolo B), requer mais tempo (ca. mais 65\%) para a evaporação, o que significa mais energia por unidade de massa de produto (ca. mais $66 \%$ ) consumida nesta operação. Os valores das variações do protocolo B para $\mathrm{C}$ na Figura 8 mostram aumentos semelhantes de EI $\left(9,45-7,87=1,58 \mathrm{Wh} \mathrm{g}^{-1}\right)$ e EI(WS $)\left(3,72-2,24=1,48 \mathrm{Wh} \mathrm{g}^{-1}\right)$, comprovando que o workup é o responsável pela diferença de energia utilizada. Em suma, é a diferença de volatilidades dos solventes usados no workup que explica o aumento do EI em $20 \%$ do protocolo B para o C (ver Tabela 3).

Quanto à TI(WS), aumenta de $\mathrm{B}$ para $\mathrm{C}$ na mesma proporção que EI(WS) (cerca de 65\%), mas como o tempo gasto no workup é muito menor que o de reação (Figura 8C), a variação na métrica global TI é baixa, passando quase despercebida.

Em conclusão, o cálculo e análise de métricas parcelares mostram-se úteis quer para aprofundar o conhecimento sobre a materialização e a energização dos processos de síntese, quer para comprovar a fiabilidade dos valores das métricas.

Finalmente, embora seja lateral ao tema deste trabalho, é interessante notar que as métricas de massa parcelares calculadas para esta síntese confirmam resultados anteriores, obtidos pela avaliação da verdura de várias outras sínteses, ${ }^{40,61}$ que mostraram que a contribuição da verdura da fase de workup é frequentemente mais penalizadora para a verdura mássica global do processo de síntese do que a da fase de reação. No entanto, no presente caso, isso pode resultar principalmente da ausência de solvente na fase de reação. Por outro lado, as métricas de energia parcelares mostram o oposto: para a reação usa-se duas vezes mais energia do que no workup.

\section{Resumo da avaliação}

A Figura 9 sumariza o procedimento de avaliação dos solventes na síntese estudada, proporcionando um panorama global dos resultados obtidos quanto aos seus efeitos na segurança, eficiência e verdura do processo. Essa sumarização gráfica dos resultados evidencia bem a complexidade da substituição dos solventes com vista a otimizar a segurança e verdura do processo de síntese. No presente caso, a substituição conduziu a uma contradição: embora a eficiência da reação de síntese não seja influenciada pelos solventes usados, o solvente mais seguro (acetato de etilo, protocolo C) proporciona piores métricas de verdura, sendo o solvente mais perigoso (éter dietílico, protocolo B) o que permite maior verdura do processo - melhores métricas de desmaterialização e desenergização (ver a Tabela 3).

Em suma, a avaliação realizada exemplifica como, na prática, pode ser difícil melhorar a verdura de um processo de síntese por substituição de solventes, e mostra como as métricas de verdura são úteis para aumentar o conhecimento sobre os resultados dos esforços de otimização. Mais concretamente, evidencia que os resultados das métricas de verdura nem sempre permitem decisões inequívocas sobre a identificação do protocolo mais benigno - o que, em princípio, deverá ser escolhido para realizar a síntese. Em casos de conflito como o presente, a decisão tem de ser baseada numa análise mais ampla da situação, envolvendo o contexto, a relevância para o utilizador, implicações para cada escolha possível, etc. Por exemplo, em 


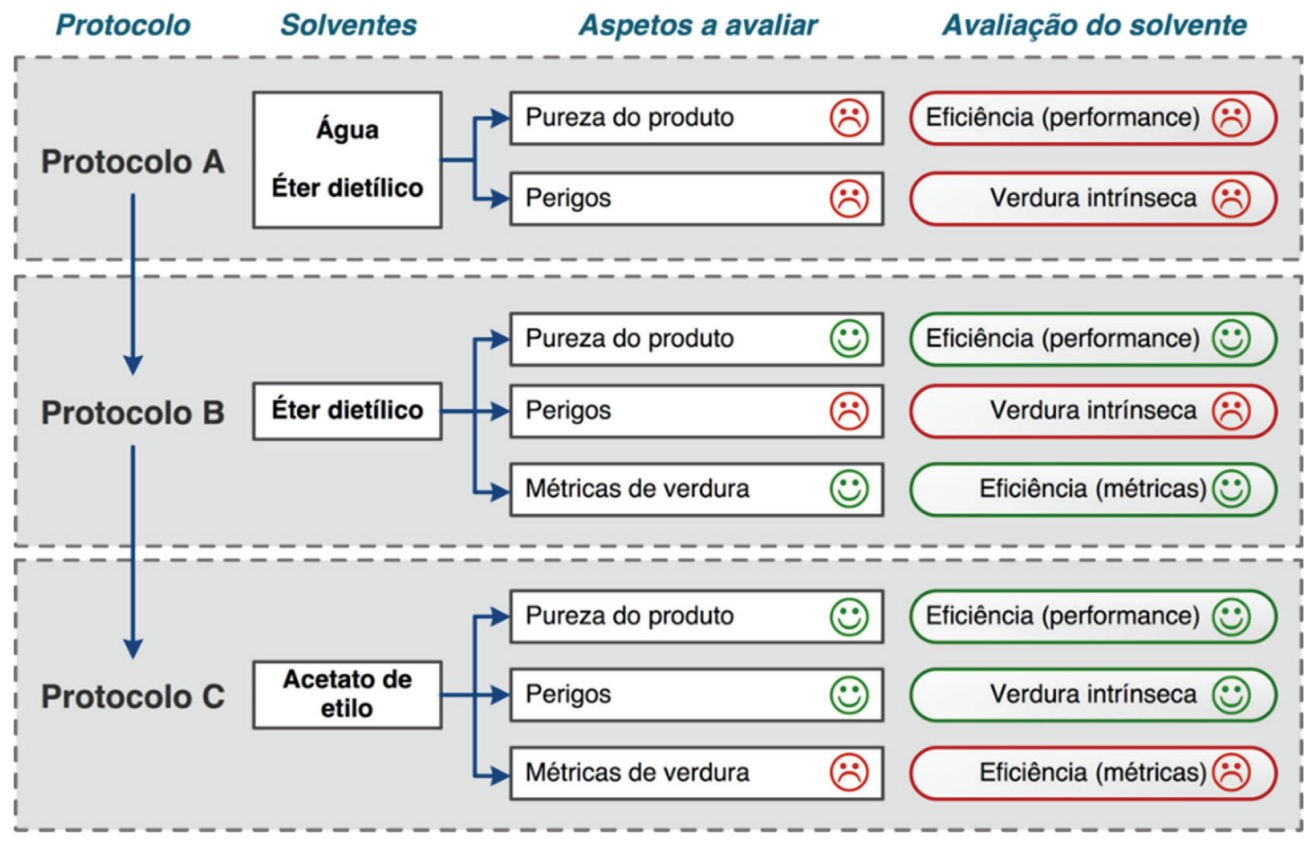

Figura 9. Análise dos protocolos da síntese do [C $\left.{ }_{6} M I M\right] C l$ usando diferentes solventes. ";)" e ":)" referem-se a um resultado favorável e desfavorável para o objetivo, respetivamente

laboratórios de índole educacional, o protocolo $\mathrm{C}$ pode ser a melhor escolha para realizar a síntese do $\left[\mathrm{C}_{6} \mathrm{MIM}\right] \mathrm{Cl}$, por o solvente ser menos perigoso e, consequentemente, permitir aos estudantes uma atividade mais segura.

\section{ESTRATÉGIA PARA IMPLEMENTAÇÃO EM LABORATÓRIOS DE ENSINO}

O procedimento proposto para avaliação do uso de solventes em sínteses é adequado para utilização num contexto de ensino de síntese verde em laboratório, podendo contribuir para uma educação química mais formativa para os estudantes, já que permite substituir a tradicional prática laboratorial de mera reprodução de protocolos obtidos na literatura por um trabalho mais criativo de pesquisa do aumento verdura. Por exemplo, uma atividade laboratorial pode iniciar-se com a seleção de um protocolo a partir de um conjunto de protocolos fornecidos, após avaliação preliminar da sua verdura com métricas adequadas para encontrar o protocolo mais verde, sendo o trabalho experimental desenvolvido a partir desse conjunto. ${ }^{40} \mathrm{Em}$ níveis mais avançados, pode continuar-se o trabalho pela otimização desse protocolo experimental para aumentar a verdura do processo sintético. Esse tipo de atividade, mais versátil, exige um envolvimento mais profundo na prática laboratorial e pode contribuir para tornar os estudantes mais conscientes da complexidade da química, já que os obriga a decidir sobre as tarefas a implementar.

No caso da síntese do $\left[\mathrm{C}_{6} \mathrm{MIM}\right] \mathrm{Cl}$, por exemplo, a atividade laboratorial de um grupo de estudantes do décimo segundo ano de escolaridade pode começar com avaliação da verdura intrínseca dos solventes envolvidos nos protocolos, usando a ferramenta SHE; em seguida, a comparação dos resultados numa discussão conjunta com o professor permitirá identificar o protocolo mais seguro (protocolo C), a ser seguido no trabalho experimental pelos estudantes. Por outro lado, no ensino superior, os estudantes poderão usar também, além da ferramenta SHE, os guias de seleção de solventes e a ferramenta de avaliação EHS, para sentir as dificuldades da avaliação dos perigos das substâncias químicas. Se houver tempo de laboratório disponível, a discussão inicial pode ser mais curta, e cada estudante (ou par de estudantes) realizar a implementação de um dos três protocolos; e após o trabalho laboratorial, uma discussão mais detalhada dos valores das métricas calculadas pelos estudantes permitirá uma comparação mais profunda dos protocolos (e, eventualmente, do nível relativo de desempenho laboratorial dos estudantes). Quando ao objetivo da síntese tradicional (obter o produto com a pureza requerida) se adicionam os objetivos referentes ao contexto ambiental da química (realizar química que preserve o ambiente), como prescrito pela QV para implementar síntese verde, essa última alternativa constitui uma abordagem mais eficaz para colocar os estudantes em contato com os desafios envolvidos na escolha ou substituição de solventes em sínteses

Muito provavelmente, uma barreira que será sentida pelos estudantes na implementação das experiências como as descritas nos cursos de primeiro e segundo anos universitários é a atividade adicional que requer a medição de mais variáveis, a energia e o tempo, até agora não incluídas nas experiências de síntese. Contudo, na atual era da informação, os estudantes estão habituados a receber informação paralelamente através de diversos canais; e, tal como sugerido numa recente edição do Journal of Chemical Education (março de 2016) sobre a crescente importância da informação em química, ${ }^{62}$ os estudantes devem ser treinados em novos procedimentos para lidar com a informação e utilizá-la. As experiências de laboratório não devem, por isso, ignorar a "era da informação" em que presentemente vivemos e podem contribuir para este treino, potenciando a aquisição de uma nova atitude que a mudança sempre requer. Na realidade, a complexidade da verdura química perseguida pela QV, uma consequência das naturezas complexas quer do sistema reacional da síntese quer da própria verdura, ${ }^{46-47}$ implica que informação extra seja necessária para a avaliação desta no processo de síntese.

\section{CONCLUSÃo}

O presente trabalho ilustra a complexidade de conseguir aumento de verdura de processos de síntese por substituição de solventes. Os resultados obtidos mostram que, apesar de ser desejável o uso de solventes menos perigosos, a mudança para um solvente mais benigno pode não conduzir a um procedimento globalmente mais verde. A substituição pode provocar perdas colaterais de verdura 
noutras dimensões, como neste caso ocorreu com a verdura energética. Assim, deve avaliar-se a eficiência do solvente no suporte das várias componentes de verdura, o que tem de ser realizado através de trabalho experimental, com cálculo de métricas adequadas.

A síntese do $\left[\mathrm{C}_{6} \mathrm{MIM}\right] \mathrm{Cl}$ é suficientemente simples para ser usada como experiência de laboratório no ensino da QV e ilustrar os problemas acarretados quando se procura otimizar a verdura em processos de síntese por substituição de solvente. O contacto com essa situação permitirá aos estudantes sentir a complexidade sistémica da química, mais precisamente, que o uso de solventes em processos como os de síntese química pode requerer compromissos variados de diversos tipos, já que esses são sistemas complexos cujo comportamento depende de numerosas variáveis com inter-relações mútuas. Apesar de a situação ser abordada num quadro reducionista, permite que os estudantes tomem consciência das questões envolvidas em tais compromissos, frequentes em QV; e, em consequência, parece adequada para promover o desenvolvimento de competências verdes, aspeto que será cada vez mais importante em futuros empregos..$^{63,64}$

Em suma, os objetivos do trabalho foram cumpridos. Por um lado, otimizou-se a síntese do $\left[\mathrm{C}_{6} \mathrm{MIM}\right] \mathrm{Cl}$ com um procedimento concebido para a avaliação do uso de solventes nesta síntese, tendose aumentado a pureza do produto obtido após eliminação de um solvente com impacto negativo na performance na síntese. Por outro, mostrou-se que a estrutura do procedimento era adequada para lidar com este tipo de otimizações que permite sistematizar a análise dos diferentes aspetos que requerem consideração, aquando da substituição de solventes. A força do procedimento resulta da utilização de um conjunto de métricas de verdura de diferentes tipos que são necessárias para avaliar as várias dimensões da verdura: métricas de massa diversas para avaliação da economia dos átomos aportados pelos reagentes que participam na reação química, bem como do nível global de materialização; métricas de energia, para avaliar a energia requerida no processo de síntese; etc. O uso de métricas parcelares permite avaliar separadamente a contribuição das fases de reação e de workup nos ganhos e perdas de verdura no processo global. Finalmente, o trabalho comprovou a importância da verdura do workup para a verdura global da síntese, mostrando que a influência pode manifestar-se por várias vias.

\section{MATERIAL SUPLEMENTAR}

Detalhes sobre a parte experimental do trabalho realizado (perigos das substâncias envolvidas, aspetos gerais, protocolos detalhados das sínteses e espetros de ${ }^{1} \mathrm{H}$ RMN, informações complementares sobre a avaliação da verdura dos solventes, com os guias de seleção e a ferramenta EHS, e métricas parcelares de massa, energia e tempo) são apresentados no Material Suplementar disponível em http:// quimicanova.sbq.org.br, na forma de arquivo PDF, com acesso livre.

\section{AGRADECIMENTOS}

O trabalho de MGTCR e JRMP recebeu apoio financeiro de UID/QUI/50006/2019 com fundos da FCT/MCTES através de fundos nacionais.

\section{REFERÊNCIAS}

1. Marcus, Y.; The Properties of Solvents, $3^{\mathrm{a}}$ ed., Wiley: Hoboken, 1998.

2. Reichardt, C.; Solvents and Solvent Effects in Organic Chemistry, $3^{\mathrm{a}}$ ed., Wiley-VCH: Hoboken, 2003.

3. Pena-Pereira, F.; Tobiszewski, M.; The Application of Green Solvents in Separation Processes. $2^{\mathrm{a}}$ ed., Elsevier: Amsterdam, 2017.

4. Clark, J. H.; Hunt, A. J.; Topi, C.; Paggiola, G.; Sherwood, J.;
Sustainable Solvents - Perspectives from Research, $2^{\mathrm{a}}$ ed., Business and International Policy, RSC: London 2017.

5. Kerton, F. M.; Marriott, R.; Alternative Solvents for Green Chemistry, $2^{\mathrm{a}}$ ed., RSC: London, 2013.

6. Nelson, W. M.; Green Solvents for Chemistry - Perspectives and Practice, $3^{\mathrm{a}}$ ed., Oxford University Press: Oxford, 2003.

7. Dicks, A. P.; Green Organic Chemistry in Lecture and Laboratory, $1^{\mathrm{a}}$ ed., CRC Press: Boca Raton, 2016.

8. Poliakoff, M.; Licence, P.; Nature 2007, 450, 810.

9. Jessop, P. G.; Can. Chem. News 2007, 59, 16.

10. Jiménez-González, C.; Curzons, A. D.; Constable, D. J. C.; Cunningham, V. L.; Int. J. Life Cycle Assess. 2004, 9, 114.

11. Constable, D. J. C.; Jimenez-Gonzalez, C.; Henderson, R. K.; Org. Process Res. Dev. 2007, 11, 133.

12. Kerton, F. M.; Alternative Solvents for Green Chemistry, RSC: London, 2009.

13. Anastas, P. T.; Warner, J. C.; Green Chemistry: Theory and Practice, Oxford University Press: Oxford, 1998.

14. Clark, J. H.; Tavener, S. J.; Org. Process Res. Dev. 2007, 11, 149.

15. Capello, C.; Fischer, U.; Hungerbuhler, K.; Green Chem. 2007, 9, 927.

16. Capello, C.; Hellweg, S.; Badertscher, B.; Hungerbühler, K.; Environ. Sci. Technol. 2005, 39, 5885-5892.

17. https://www.ethz.ch/content/specialinterest/chab/chemical-nbioengineering/set-group/en/research/downloads/software---tools/ ecosolvent.html, acessada em Agosto 2019.

18. Jessop, P. G.; Green Chem. 2011, 13, 1391.

19. Henderson, R. K.; Jimenez-Gonzalez, C.; Constable, D. J. C.; Alston, S. R.; Inglis, G. G. A.; Fisher, G.; Sherwood, J.; Binks, S. P.; Curzons, A. D.; Green Chem. 2011, 13, 854.

20. Alder, C. M.; Hayler, J. D.; Henderson, R. K.; Redman, A. M.; Shukla, L.; Shuster, L. E.; Sneddon, H. F.; Green Chem. 2016, 18, 3879.

21. Alfonsi, K.; Colberg, J.; Dunn, P. J.; Fevig, T.; Jennings, S.; Johnson, T. A.; Kleine, H. P.; Knight, C.; Nagy, M. A.; Perry, D. A.; Stefaniak, M.; Green Chem. 2008, 10, 31.

22. Prat, D.; Pardigon, O.; Flemming, H.-W.; Letestu, S.; Ducandas, V.; Isnard, P.; Guntrum, E.; Senac, T.; Ruisseau, S.; Cruciani, P.; Hosek, P.; Org. Process Res. Dev. 2013, 17, 1517.

23. Diorazio, L. J.; Hose, D. R. J.; Adlington, N. K.; Org. Process Res. Dev. 2016, 20, 760

24. http://www.acs.org/content/dam/acsorg/greenchemistry/ industriainnovation/roundtable/acs-gci-pr-solvent-selection-guide.pdf, acessada em Agosto 2019.

25. https://www.chem21.eu/project/chem21-solvent-selection-guide/, acessada em Agosto 2019.

26. Prat, D.; Wells, A.; Hayler, J.; Sneddon, H.; McElroy, C. R.; AbouShehada, S.; Dunn, P. J.; Green Chem. 2016, 18, 288.

27. Prat, D.; Wells, A.; Hayler, J.; Sneddon, H.; McElroy, C. R.; AbouShehada, S.; Dunn, P. J.; Green Chem. 2015, 17, 4848.

28. http://www.imi.europa.eu, acessada em Agosto 2019.

29. Prat, D.; Hayler, J.; Wells, A.; Green Chem. 2014, 16, 4546.

30. Perez-Vega, S.; Ortega-Rivas, E.; Salmeron-Ochoa, I.; Sharratt, P. N.; Environment, Development and Sustainability 2013, 15, 1.

31. Alves Costa Pacheco, A.; Sherwood, J.; Zhenova, A.; McElroy, C. R.; Hunt, A. J.; Parker, H. L.; Farmer, T. J.; Constantinou, A.; De Bruyn, M.; Whitwood, A. C.; Raverty, W.; Clark, J. H.; ChemSusChem 2016, 9,3503.

32. Murray, P. M.; Bellany, F.; Benhamou, L.; Bucar, D. K.; Tabor, A. B.; Sheppard, T. D.; Org. Biomol. Chem. 2016, 14, 2373.

33. Koller, G.; Fischer, U.; Hungerbühler, K.; Ind. Eng. Chem. Res. 2000, 39,960 .

34. https://www.ethz.ch/content/specialinterest/chab/chemical-nbioengineering/set-group/en/research/downloads/software---tools/ehstool.html, acessada em Agosto 2019. 
35. Pinto, J. R. M.; Ribeiro, M. G. T. C.; Machado, A. A. S. C.; Química Boletim da S. P. Q. 2017, 146, 175-186.

36. McKenzie, L. C.; Huffman, L. M.; Hutchison, J. E.; Rogers, C. E.; Goodwin, T. E.; Spessard, G. O.; J. Chem. Educ. 2009, 86, 488.

37. Aktoudianakis, E.; Chan, E.; Edward, A. R.; Jarosz, I.; Lee, V.; Mui, L.; Thatipamala, S. S.; Dicks, A. P.; J. Chem. Educ. 2009, 86, 730.

38. Dicks, A. P.; Green Chem. Lett. Rev. 2009, 2, 87.

39. Dicks, A. P.; Green Chem. Lett. Rev. 2009, $2,9$.

40. Duarte, R. C. C.; Ribeiro, M. G. T. C.; Machado, A. A. S. C.; J. Chem. Educ. 2015, 92, 1024.

41. Soares, P.; Fernandes, C.; Chavarria, D.; Borges, F.; J. Chem. Educ. 2015, 92, 575

42. Dicks, A. P.; J. Chem. Educ. 2015, 92, 405.

43. Mistry, N.; Fitzpatrick, C.; Gorman, S.; J. Chem. Educ. 2016, 93, 1091.

44. Goodwin, T. E.; J. Chem. Educ. 2004, 81, 1187.

45. Machado, A. A. S. C.; Quim. Nova 2014, 37, 1094.

46. Machado, A. A. S. C.; Introdução às Métricas da Química Verde - Uma visão sistêmica, EdUFSC: Florianópolis, 2014.

47. Machado, A. A. S. C. In Worldwide Trends in Green Chemistry Education; Zuin, V., Mammino, L., eds.; RSC: London, 2015, pp 111136.

48. Committee on Metrics for Global Change Research (CMGCR) - US National Research Council, Thinking Strategically - The Appropriate Use of Metrics for the Climate Change Science Program. US National Academy Press: 2005, disponível em: http://www.nap.edu/catalog. php?record_id=11292, acessado em Agosto 2019.

49. Committee on Industrial Environmental Performance Metrics (CIEPM) - US Academy of Engineering, Industrial Environmental Performance Metrics - Challenges and Opportunities. US National Academy Press: 1999, disponível em: http://www.nap.edu/catalog.php?record_id=9458, acessado em Agosto 2019.
50. Calvo-Flores, F. G.; ChemSusChem 2009, 2, 905.

51. Borges, M. J.; Ribeiro, M. G. T. C.; Machado, A. A. S. C.; XVIII Encontro Luso-Galego de Química, Vila Real, 2012; pp. 209, disponível em http://educa.fc.up.pt/investigacao_artigo.php?id=135, acessado em Agosto 2019

52. Pires, T. C. M.; Ribeiro, M. G. T. C.; Machado, A. A. S. C.; Quim. Nova 2018, 41, 335 .

53. Costa, D. A.; PhD Thesis, Universidade do Porto, Portugal, 2011.

54. Costa, D. A.; Ribeiro, M. G. T. C.; Machado, A. A. S. C.; XVIII Encontro Luso-Galego de Química, Vila Real, 2012; pp. 203, disponível em http:// educa.fc.up.pt/investigacao_artigo.php?id=138, acessado em Agosto 2019.

55. Stark, A.; Ott, D.; Kralisch, D.; Kreisel, G.; Ondruschka, B.; J. Chem. Educ. 2010, 87, 196.

56. http://educa.fc.up.pt/catalogo/pt/construcao_she, acessada em Agosto 2019.

57. http://educa.fc.up.pt/catalogo/pt/avaliacao/s5, acessada em Agosto 2019.

58. http://educa.fc.up.pt/catalogo/pt/avaliacao/34, acessada em Agosto 2019.

59. http://educa.fc.up.pt/catalogo/pt/avaliacao/56, acessada em Agosto 2019.

60. Ribeiro, M. G. T. C.; Machado, A. A. S. C.; Green Chem. Lett. Rev. 2012, 6,1 .

61. Duarte, R. C; PhD Thesis, Universidade do Porto, Portugal, 2016.

62. Baysinger, G.; J. Chem. Educ. 2016, 93, 401.

63. European Centre for the Development of Vocational Training (CEDEFOP), European Synthesis Report, 2010.

64. Haack, J. A.; Hutchison, J. E.; ACS Sustainable Chem. Eng. 2016, 4, 5889 . 